\title{
한반도의 $\mathrm{CMORPH}$ 위성강수자료 정확도 평가
}

\author{
김주훈 · 김경탁 + · 최윤석 \\ 한국건설기술연구원 수자원연구실
}

\section{Fitness Evaluation of CMORPH Satellite-derived Precipitation Data in KOREA}

\author{
Joo Hun Kim · Kyung Tak Kim + - Youn Seok Choi
}

Water Resources Research Division, Korea Institute of Construction Technology, Goyangsi, Gyeonggido, Korea

요 약

본 연구에서는 $\mathrm{NOAA} \mathrm{CPC}$ 에서 제공하고 있는 인공위성을 이용한 광역적 강수량 추정 자료인 $\mathrm{CMORPH}$ 와 지상 관측자료 와의 비교를 통해 위성으로부터 유도된 강수자료의 정확도 및 활용 가능성 등 수자원 분야 이용 가능성을 분석하는 것을 목적으로 하였다. 2002-2011년의 10년간의 자료를 분석한 결과 1 일 누가강수의 상관계수가 평균 0.87 정도로 분석되었으나, 연간 총강수량은 약 4 5배 정도 차이가 나는 것으로 분석되었다. 또한 시간해상도가 커짐에 따라 RMSE의 변동성이 작 아지는 것으로 분석되었다. 유역 규모에 따른 분석에서 유역 규모가 커질수록 강수자료의 정확도에 대한 평가가 향상되 는 것으로 분석되었다.

핵심용어 : 위성영상, 위성유도 강수, $\mathrm{CMORPH}$, 공간규모, 시간해상도

\begin{abstract}
This study analyzes the application possibilities of the satellite-derived precipitation to water resources field. Precipitation observed by ground gauges and climate prediction center morphing method (CMORPH) which is global scale precipitation estimated by National Oceanic and Atmospheric Administration Climate Prediction Center (NOAA CPC) using satellite images are compared to evaluate the quality of precipitation estimated from satellite images. Precipitation data from 10-years (2002 to 2011) is applied. The correlation coefficient of 1-day cumulative precipitation is 0.87 , but the 1-year precipitation is 4 to 5 times different. The variability of root mean square error (RMSE) become smaller as temporal resolution lower. On the results for the watershed scale, the precipitation from gauges and CMORPH shows better agreement as the watershed become larger.
\end{abstract}

Keywords : CMORPH, Satellite derived precipitation, Satellite Image, Spatial size, Temporal resolution

\section{1. 서 론}

최근 들어 강조되고 있는 수자원분야의 이슈는 미래 성장 동력으로서 '21세기 블루골드'로 불릴 만큼 시장 잠재력이 큰 물 산업의 해외 진출을 위한 시도이다. $\mathrm{GWI}(G l o b a l$ Water Intelligence)에 따르면 세계 물 시장 은 약 5천억 달러 규모(2010년 기준)로서 2025년 미래 물산업 시장은 2007년 대비 약 2.5 배 정도 성장할 것으 로 예측하고 있으나, 우리 기업의 해외 물산업 진출규 모는 2011년 기준 약 14.2억 달러로 세계 물시장 점유 율은 $0.4 \%$ 수준에 불과하다. 이에 2012년 5월 녹색성장 위원회에서는 '물산업 육성 및 해외진출 활성화 방안 이행점검과 향후 대책'을 주제로 사업이행 점검결과를
논의하였으며, 2012년 8월 ‘국회환경포럼'에서는 물산업 육성 정책과 법제 개선방안을 주제로 토론회가 개최된 바 있다(Lee, 2012).

수문학적, 지형학적 특성이 강조되는 수문/수자원 분 야의 기술을 해외에 수출하기 위해서는 해당 국가의 수 문기상학적 특성을 미리 이해하는 것이 중요하며, 수문 순환 연구의 기초라 할 수 있는 강수 특성의 파악은 매 우 핵심적인 사항이라 할 수 있다.

그러나 대부분의 물 산업 진출 대상 국가는 미계측 유역이 많고 지상에서 계측된 수문 자료가 부족한 실정 이며 이럴 경우 기상 위성을 이용하여 추정된 강수량 자료가 해당 지역의 강수 특성을 파악하는데 중요한 자 료로 이용될 수 있다.

+ Corresponding author : ktkim1@kict.re.kr 
위성으로부터 유도된 강수자료는 지상 관측자료와 비교하였을 때 인도네시아의 경우 시간강수자료는 $R^{2}$ 이 0.8874 , 일일자료는 $0.9 \sim 0.94$ 정도의 값을 갖는다고 언급하고 있으나(Apip et al., 2010), 남아프리카 두 개 유역 중 아마존 유역 일일강수의 경우 $R^{2}$ 가 0.1 , Iguaçu 유역의 년간 강수비교에서는 $R^{2}$ 가 0.72 의 값을 갖는다고 제시하고 있다(Augusto, 2010). 또한 아프리카 나일강의 Gilgel Abbay 유역의 시간 강수 비교시 상관 계수가 0.27 이하로 매우 낮은 상관관계를 갖는다고 제 시하고(Alemseged et al., 2012) 있어 대륙별, 연구자들 사이에 큰 차이를 보이고 있다.

본 연구에서는 NOAA CPC (National Oceanic and Atmospheric Administration Climate Prediction Center)에 서 제공하고 있는 인공위성을 이용한 광역적 강수량 추 정 자료인 CMORPH(Climate prediction center MORPHing method)에 대하여 지상 관측자료와의 비교를 통해 한반 도에서의 위성으로부터 유도된 강수자료의 정확도 및 활용 가능성 등 수자원 분야 이용 가능성을 분석하는 것을 목적으로 하였다.

\section{CMORPH}

위성자료를 이용한 강수추정 방법은 가시광선(VIS) 및 적외선 영상(IR)을 이용하는 방법과 마이크로파가 강수층을 통과하면서 강수입자에 의해 산란되거나 또 는 강수층에서 마이크로파가 방출되는 성질을 이용하 는 방법, 그리고 이 두 방법을 융합하여 강수량을 추 정하는 혼합 강수추정 방법(combined precipitation estimation techniques) 등이 있다. CMORPH, TMPA (TRAMM Multi-satellite Precipitation Analysis), GSMaP (Global Satellite Mapping of Precipitation) 등이 혼합 강 수추정 방법으로 생산되어 제공되는 대표적인 강수추 정 자료이다.

$\mathrm{CMOPRH}$ 는 $\mathrm{NOAA} \mathrm{CPC}$ 에서 생산하여 제공되는 것 으로 정지궤도위성의 적외선 자료로부터 유도되는 모 션 벡터(motion vector)와 수동 마이크로파(passive microwave) 위성 자료로부터 유도된 30 분 전지구 강수 추정치를 제시하는 기법을 이용하고 있다. 즉, $\mathrm{CMORPH}$ 는 수동 마이크로파 자료로부터 유도되는 상 대적으로 높은 정량적 강수추정치를 전달하기 위해 30 분 간격으로 정지궤도위성의 IR 영상으로부터 유도된 모센벡터(motion vectors)를 이용한다. 시간가중 선형 보 간법(time-weighted linear interpolation)에 의해 마이크로 파 센서의 관측 시간 사이의 강수특성의 형태와 강도 를 수정(morphing)하는 기법을 이용하는 것이다.

이와 같은 방법은 적외선 온도장에 독립적인 시공간 적으로 완전한 마이크로파로 유도되는 강수해석기법을
의미한다. CMORPH는 마이크로파 추정치를 단순히 평 균하거나, 마이크로파 정보를 얻을 수 없을 때 적외선 자료로부터 추정된 강수량을 단순히 섞어서 사용하는 방법보다 괄목할 만한 성과의 증진을 보이고 있다.

DMSP $13,14, \& 15$ 위성의 SSM/I, 그리고 NOAA-15, 16, $17 \& 18$ 위성의 AMSU-B(Advanced Microwave Sounding Unit), NASA Aqua 위성의 AMSR-E(Advanced Microwave Scanning Radiometer for EOS), TRMM spacecraft의 TMI(TRMM Microwave Imager)에서 각각 제공되는 마이크로파 관측 값을 이용하여 강수량을 추 정하고 있다. $\mathrm{CMORPH}$ 의 지역적 제공범위는 $60^{\circ} \mathrm{N}-60^{\circ} \mathrm{S}$ 이고 2002년 12월부터 제공되고 있으며 30분 간격으로 전지구 강수량 추정 값을 생산하여 제공하고 있다.

$\mathrm{NOAA} \mathrm{CPC}$ 의 $\mathrm{CMORPH}$ 강수량 추정 자료는 $30 \mathrm{~min} / 8 \mathrm{~km}, 3 \mathrm{hr} / 0.25^{\circ}, 1 \mathrm{day} / 0.25^{\circ}$ 의 3 가지 종류의 시간해 상도/공간해상도를 갖는 데이터를 제공하고 있다.

또한, $\mathrm{NOAA} \mathrm{CPC}$ 에서는 $\mathrm{CMORPH}$ 강수량 추정 자료 는 18 시간후에 제공되고 있어 사용자들의 요구에 의해 보다 빠른 시일에 강수량 추정 자료를 제공할 목적으 로 $\mathrm{QMORPH}$ 자료를 생산하여 제공하고 있다. $\mathrm{QMORPH}$ 강수량 추정 자료는 $\mathrm{CMORPH}$ 와 유사하나 수동 마이크로파 강수 특성을 IR 자료를 이용하여 모 핑 없이 해당시간의 전방향(forward)으로만 전파하는 방 법을 이용하고 있다.

\subsection{CMORPH 변환 자료 포맷}

미국 기상청 $\mathrm{NOAA}$ 의 전지구 기후자료 중 $\mathrm{CMORPH}$ data는 $0.25 \times 0.25^{\circ}$ 공간해상도의 일일자료와 3 시간 누 적강수자료, 그리고 $8 \times 8 \mathrm{~km}$ 의 30 분 강수자료를 제공 하고 있다. 이들 데이터 중에서 3 시간 누적 강수자료는 UNIX DATA 압축 방식을(.Z) 사용하며 해당 시점 별 총 16 개의 $\mathrm{BINARY} \mathrm{RECORD}$ 가 존재한다. 각 레코드의 사이즈는 $1440 \times 480(\mathrm{REAL} \times 4)$ 자료간격은 $\mathrm{LAT} / \mathrm{LON}$ 모 두 0.25 도이며 단위는 “ $\mathrm{mm} / \mathrm{hr}$ "를 사용, nodata value는 “-9999”로 저장되어 있다. 격자 구성은 X축 $0.125 \mathrm{E}, \mathrm{Y}$ 축 $59.875 \mathrm{~N}$ 을 시점으로 0.25 도씩 증가한다.

한편, 30 분 강수자료의 포맷은 UNIX DATA 압축 방 식을(.Z) 사용하며 해당 시점 별 총 6 개의 BINARY $\mathrm{RECORD}$ 가 존재하며, 이때 $\mathrm{RECORD}$ 는 각각 강수 2 개, 시간 2개, 위성 ID 2개로 구성된다. 각 레코드의 사이 즈는 4948×1649 (CHARACTER Data Type) 간격은 LON 방향은 0.072756669 도, LAT 방향은 0.072771377 도이다. Nodata value 는 " 255 ”로 저장된다. 강수의 경우 단위는 " $\mathrm{mm} / \mathrm{hr}$ “ scale은 0.2 가 적용되며, 시작 격자 위치는 X 축 $0.036378335 \mathrm{E}, \mathrm{Y}$ 축 $59.963614 \mathrm{~N}$ 이다. 


\section{2 자료 변환 모듈 개발}

개발된 $\mathrm{CMORPH}$ 자료의 변환 포맷은 Fig. 2에서 보 여지는 바와 같이 이미지 파일, $\mathrm{OGC}$ 의 $\mathrm{KML}$ 파일, 그리 고 $\mathrm{ESRI}$ 의 $\mathrm{ASCI}$ 파일 포맷의 3 개의 포맷으로 변환할 수 있다. 이미지 파일은 해당 시점의 CMORPH 바이너 리 DATA를 직관적인 이미지로 조회가 가능하며, $\mathrm{CMORPH}$ 강수 데이터의 시계열적인 특성을 용이하게 파악할 수 있다. $\mathrm{KML}$ 포맷은 $\mathrm{NOAA}$ 의 전지구 데이터 (CMORPH의 강수추정 데이터)를 $\mathrm{OGC}$ 표준 $\mathrm{KML}$ 형태 로 제공하는 기능을 포함하고 있으며, 이를 통하여
$\mathrm{KML}$ 을 지원하는 다양한 $\mathrm{S} / \mathrm{W}$ 에서 가시화 할 수 있다. 또한, GIS범용 수치 래스터 포맷(ESRI ASC)으로 변환 하며 이를 통하여 자료의 수치 데이터를 조회/분석용으 로 활용할 수 있다. Fig. 1은 개발된 NOAA CMORPH 변환 모듈이고 Fig. 2 는 변환 모듈을 통해 변환된 $\mathrm{CMORPH}$ 의 2012년 8월 23일 UTC15의 강수자료를 예 시한 것이다.

본 연구에서는 Fig. 2의 이미지 파일과 같이 전지구 에 대하여 경위도 좌표를 갖는 강수자료에 대하여 아 스키 포맷 파일의 한반도 지역을 클리핑하고 $\mathrm{TM}$ 좌표 로 변환한 후 지상관측자료와 정확도 검증을 하였다.

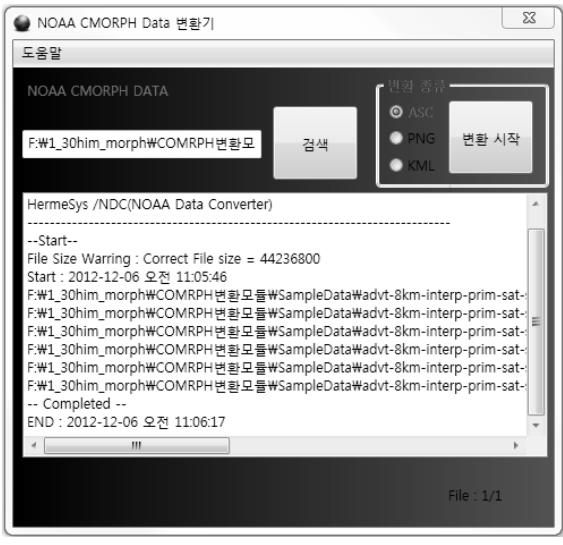

Fig. 1. CMORPH Conversion Module

\section{3. $\mathrm{CMORPH}$ 강수자료 평가}

\section{1 적용지역}

적용대상 지역은 한반도 남한지역과 낙동강 유역, 금 호강 유역의 3 개 유역으로 구분하여 적용하였다. 한반도 남한지역에 대한 적용은 연간 총강수량과 공간적 분포 에 대한 평가를 수행하고 낙동강 유역 및 금호강 유역 에 대해서는 시간해상도에 따른 분석과 공간규모에 따 른 분석을 수행하기 위하여 선정하였다.

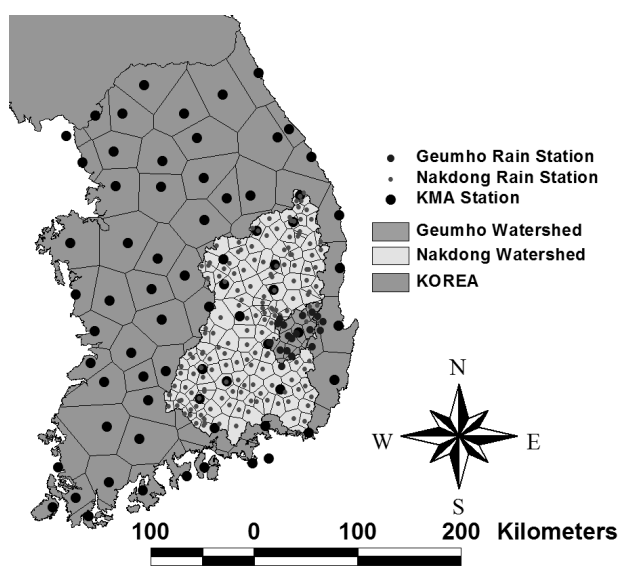

Fig. 3. Study area

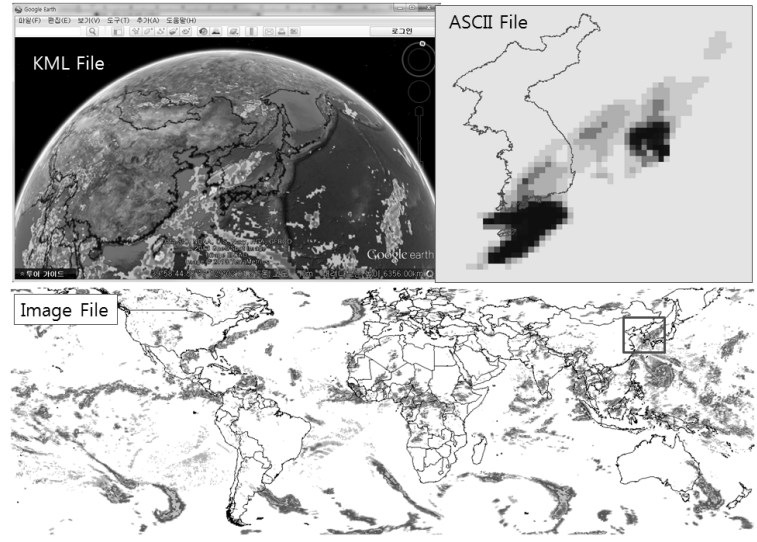

Fig. 2. CMORPH data(20120823 15UTC)

\section{2 일일강수량 비교}

한반도 남한지역의 위성영상으로부터 유도된 $\mathrm{CMORPH}$ 강수자료와의 비교를 위해 CMORPH $3 \mathrm{hr} / 0.25^{\circ}$ 누가강수 자료와 기상청의 일일강수자료의 비교를 통해 $\mathrm{CMORPH}$ 강수자료의 정확도를 평가하였다. 기상청의 강수자료는 2003년 1월 1일부터 2011년 12월 31일까지 의 일일강수자료를 이용하였으며, 기상관측소는 한반도 남쪽의 기상관측소 중 제주도, 울릉도 등에 위치하는 기 상관측소 등을 제외한 총 69 개 기상관측소의 자료를 적 용하였다.

$\mathrm{CMORPH}$ 자료는 $\mathrm{CMORPH}$ 자료 변환 모듈을 통해 변 환된 ASCII파일의 평균값을 계산하였고, 기상청의 일일 강수자료는 티센 가중법에 의한 면적평균 방법을 이용 하여 지상관측소의 평균값을 계산하였다. 이 두 자료의 일일 면적평균 강수량에 대하여 상관분석을 통해 $\mathrm{CMORPH}$ 자료의 정확도를 평가하였다.

분석결과 지상관측지점의 강수량과 $\mathrm{CMORPH}$ 강수자 료의 상관계수는 0.82 에서 0.92 정도로 매우 높은 상관 관계가 있음을 보여주고 있으며(Fig. 4), 상대오차 평균 은 0.79 로 나타나는 것으로 분석되었다. Table 1에서 보는바와 같이 RMSE는 평균 $72.5, \mathrm{nRMSE}$ 평균 0.95 , 그리고 Nash-Sutcliffe 효율계수는 0.24정도로 나타났는데 
Table 1. Comparison of CMORPH and Gauge daily precipitation

\begin{tabular}{c|c|c|c|c|c|c|c}
\hline \multirow{2}{*}{ Item } & \multicolumn{2}{|c|}{ Total precipitation(mm/yr) } & \multicolumn{5}{c}{ Statistic Analysis } \\
\cline { 2 - 8 } year & CMORPH & Gauge & CC & relative error & RMSE & nRMSE & N-S \\
\hline \hline 2003 & 417.6 & $1,831.6$ & 0.88 & 0.77 & 100.1 & 1.03 & 0.28 \\
\hline 2004 & 382.2 & $1,440.2$ & 0.92 & 0.73 & 74.1 & 0.67 & 0.37 \\
\hline 2005 & 275.0 & $1,291.9$ & 0.86 & 0.79 & 56.2 & 0.88 & 0.23 \\
\hline 2006 & 257.8 & $1,421.7$ & 0.91 & 0.82 & 85.0 & 0.94 & 0.22 \\
\hline 2007 & 282.6 & $1,445.3$ & 0.90 & 0.80 & 65.1 & 1.04 & 0.23 \\
\hline 2008 & 186.1 & 991.7 & 0.88 & 0.81 & 44.2 & 0.75 & 0.21 \\
\hline 2009 & 248.4 & $1,217.9$ & 0.82 & 0.80 & 68.9 & 0.90 & 0.25 \\
\hline 2010 & 328.7 & $1,437.6$ & 0.83 & 0.77 & 56.4 & 0.97 & 0.26 \\
\hline 2011 & 256.8 & $1,677.2$ & 0.87 & 0.85 & 102.2 & 1.35 & 0.15 \\
\hline mean & 292.8 & $1,417.2$ & 0.87 & 0.79 & 72.5 & 0.95 & 0.24 \\
\hline
\end{tabular}

이는 지상관측자료와 $\mathrm{CMORPH}$ 자료의 총강수량의 차이 가 큰 원인에 기인하는 것으로 판단되나 앞서 언급한 바와 같이 상관계수는 평균 0.87 로 매우 높은 상관관계 를 나타내고 있다.

총강수량의 경우 지상관측지점의 강수량과 비교하여
$\mathrm{CMORPH}$ 강수자료는 평균 $20.6 \%(15.3 \% \sim 26.5 \%)$ 정도 로 과소하게 추정되었다. Sohn et al.(2006)의 연구결과에 의하면 여름철 평균 분포는 명백하게 상당히 과소평가 된다고 언급하고 있으며, 이는 본 연구에서도 같은 결론 으로 나타나고 있다.
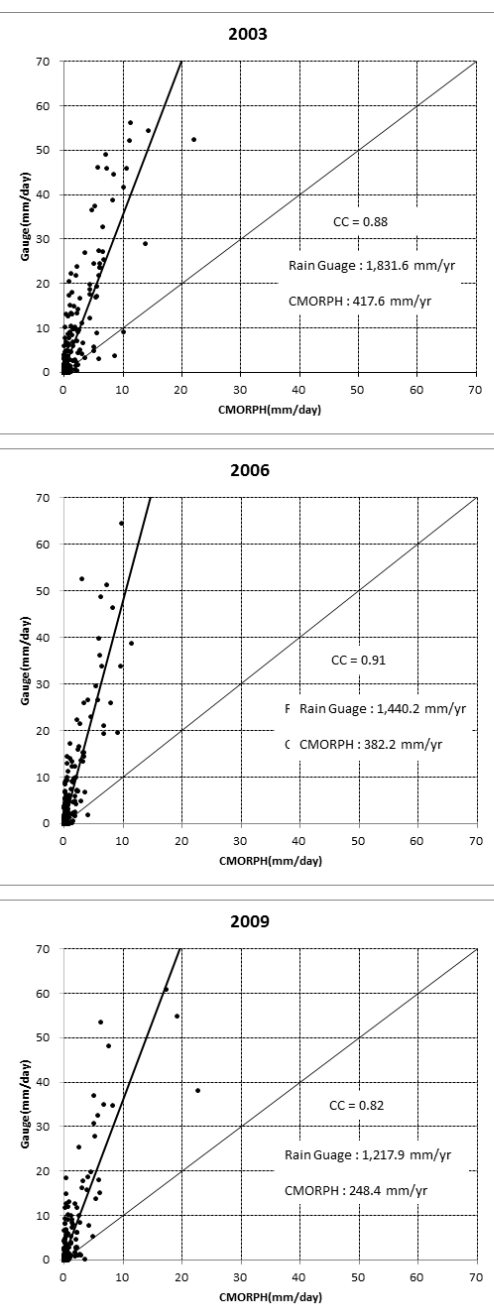
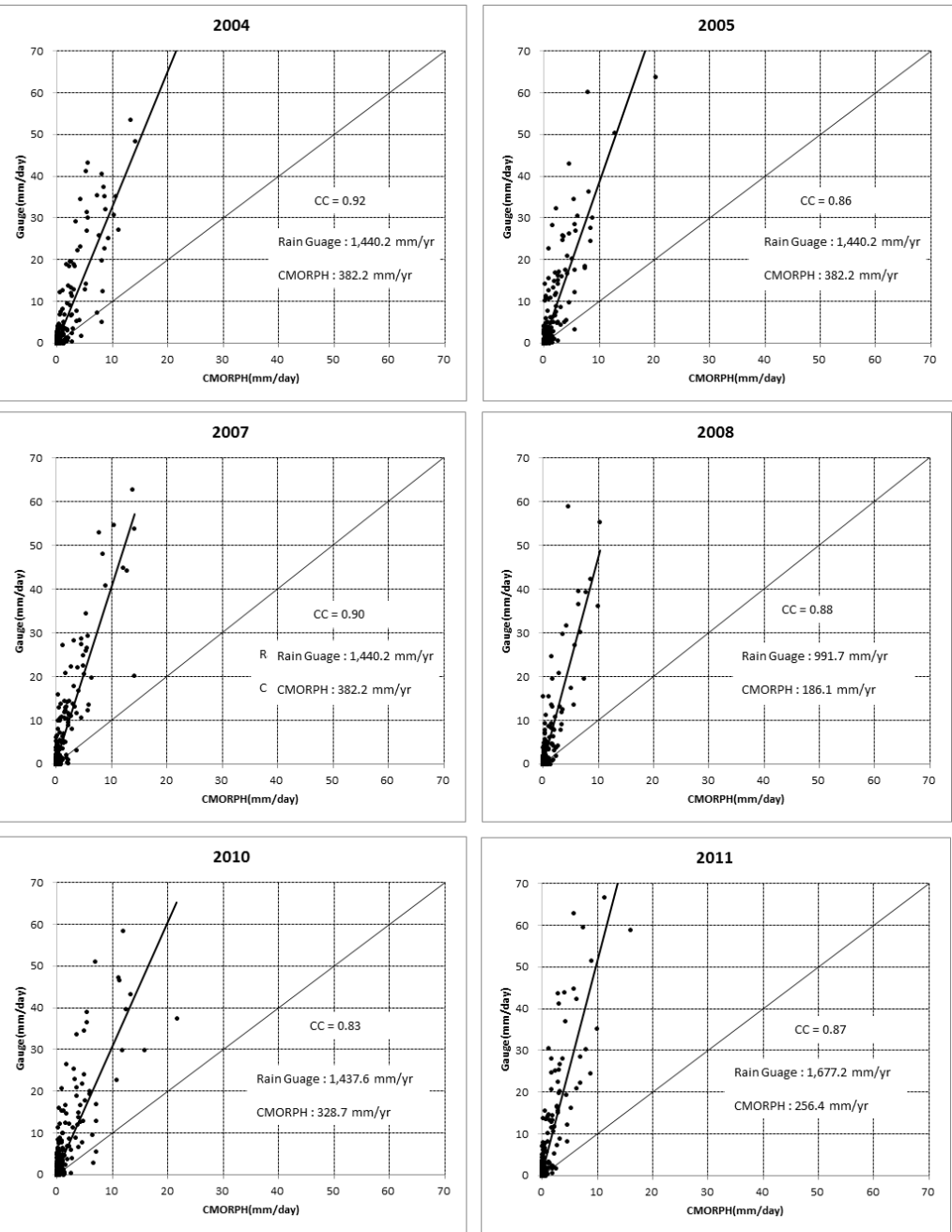

Fig. 4. Comparison of CMORPH and Gauge daily precipitation 
Fig. 5는 연간 강수자료의 공간분포도를 나타낸 것으 로 한반도 중부 및 남부지역의 높은 연간 강우분포와

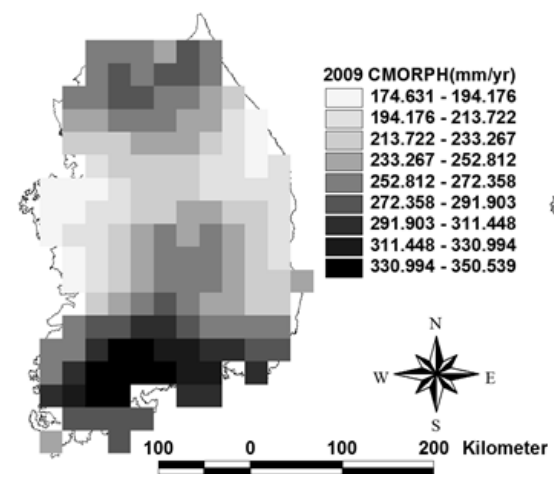

동서해안의 낮은 연간 강우분포가 유사하게 분포되는 것으로 분석되었다.

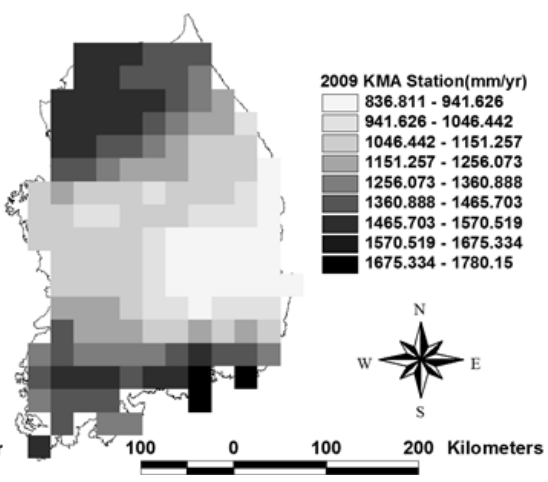

Fig. 5. Comparison of $\mathrm{CMORPH}$ and Gauge precipitation

\section{3 시간 강수 자료 비교}

시간 강수자료의 시간해상도에 따른 비교를 위해 $\mathrm{CMORPH} 30$ 분 강수자료에 대하여 1시간 누가강수, 3 시 간 누가강수를 계산하였고, 30 분, 1 시간, 3 시간에 대한 정확도를 평가하였다. 또한 유역면적의 크기에 따른 정 확도를 평가하기 위하여 Fig. 1과 같이 낙동강 유역(유역 면적 $23,690 \mathrm{~km}^{2}$ )과 낙동강 유역내의 금호강 유역(유역면 적 $1,561.5 \mathrm{~km}^{2}$ )을 선정하여 분석하였다.

두 유역에 대하여 강수사상은 2011년 2개 강수사상과 2012년 6개의 강수사상을 선정하여 적용하였다. 3시간 강우자료 비교는 $3 \mathrm{hr} / 0.25^{\circ}$ 자료를 수집하였고, 30 분 및 1 시간 강수자료 비교는 $30 \mathrm{~min} / 8 \mathrm{~km}$ 자료를 수집하여 적용하 였다. 한편, $30 \mathrm{~min} / 8 \mathrm{~km}$ 자료의 경우 준실시간으로 제공되 는 자료로서 2011년의 2개 사상에 대한 자료는 획득하 지 못하여 2012년 6개 사상에 대하여 적용하였다.

낙동강 유역의 지상강우관측소는 국토해양부에서 운 영하는 181 개 강우관측소에 대하여, 그리고 금호강 유역 의 19 개 지상 강우 관측소의 10 분 강우자료를 누가하여 30 분 강우, 1 시간 강우 및 3 시간 지상관측 강우자료를
산정하였다.

산정된 지상강우관측 자료를 기준으로 위성으로부터 유도된 강수자료인 $\mathrm{CMORPH}$ 자료에 대한 정확도 평가를 수행하였다.

\subsubsection{3 시간 누가강우 비교}

Table 2는 낙동강 및 금호강 유역의 3시간 누가강수 정확도 및 이에 대한 통계값의 결과를 나타낸 것이다. 분석결과 낙동강유역의 경우 상관계수는 0.43 에서 0.86 정도로 비교적 상관성이 높은 것으로 분석되었으나, $\mathrm{RMSE}$ 의 경우 값의 차이가 크게 나타나고, Nash-Sutcliffe(N-S) 효율계수는 낮은 값을 나타냈는데 이 는 지상관측자료와 $\mathrm{CMORPH}$ 자료의 총강수량의 차이가 큰 원인에 기인하는 것으로 판단된다.

금호강 유역의 경우 3 시간 누가강수량 분석결과 8 개 강수사상의 평균 상관계수는 0.45 정도로 '비교적 강한 양의 상관관계'를 갖는 정도의 상관계수 값으로 평가되 었다. 또한 RMSE도 평균 8.52로 변동성이 큰 것으로 분 석되었고, N-S계수도 낮은 값을 나타내고 있다.

Table 2. Comparison of CMORPH and Gauge data for $3 \mathrm{hr}$ accumulation precipitation

\begin{tabular}{|c|c|c|c|c|c|c|c|c|c|c|c|c|}
\hline \multirow{2}{*}{$3 \mathrm{hr}$} & \multicolumn{2}{|c|}{$\mathrm{CMORPH}(\mathrm{mm})$} & \multicolumn{2}{|c|}{ Gauge(mm) } & \multicolumn{2}{|c|}{$\mathrm{CC}$} & \multicolumn{2}{|c|}{ RMSE } & \multicolumn{2}{|c|}{ nRMSE } & \multicolumn{2}{|c|}{$\mathrm{N}-\mathrm{S}$} \\
\hline & ND & GH & ND & $\mathrm{GH}$ & ND & $\mathrm{GH}$ & ND & $\mathrm{GH}$ & ND & GH & ND & GH \\
\hline$\# 01$ & 11.38 & 10.68 & 116.72 & 101.45 & 0.43 & 0.26 & 8.35 & 7.80 & 0.43 & 0.40 & -2.39 & -1.77 \\
\hline$\# 02$ & 43.95 & 48.06 & 208.69 & 253.62 & 0.81 & 0.66 & 12.35 & 17.34 & 0.75 & 0.48 & -2.23 & -1.03 \\
\hline$\# 03$ & 14.50 & 10.00 & 50.25 & 43.53 & 0.52 & 0.19 & 5.61 & 5.96 & 0.56 & 0.60 & -2.94 & 0.27 \\
\hline$\# 04$ & 2.14 & 3.59 & 23.50 & 24.63 & 0.71 & 0.77 & 7.64 & 8.77 & 0.73 & 0.74 & -3.70 & 0.12 \\
\hline$\# 05$ & 25.91 & 29.20 & 117.99 & 117.07 & 0.71 & 0.33 & 4.60 & 6.65 & 0.30 & 0.25 & 0.20 & 0.16 \\
\hline$\# 06$ & 18.25 & 16.06 & 69.35 & 66.02 & 0.84 & 0.26 & 4.56 & 5.92 & 0.31 & 0.41 & -0.16 & 0.22 \\
\hline$\# 07$ & 28.42 & 29.02 & 133.90 & 173.36 & 0.46 & 0.47 & 6.22 & 10.89 & 0.35 & 0.31 & -1.15 & 0.16 \\
\hline$\# 08$ & 6.42 & 2.23 & 75.74 & 34.86 & 0.86 & 0.65 & 4.83 & 4.83 & 0.33 & 0.33 & -0.35 & -0.35 \\
\hline 평균 & 18.87 & 18.60 & 99.52 & 101.82 & 0.67 & 0.45 & 6.77 & 8.52 & 0.47 & 0.44 & -1.59 & -0.28 \\
\hline
\end{tabular}

ND : Nakdong watershed, GH : Geumho watershed 


\subsubsection{1시간 누가강수 비교}

Table 3은 두 유역의 1시간 누가강수 정확도 및 이에 대한 통계값의 결과를 나타낸 것이다. 낙동강 유역의 경 우 1 시간 자료에 대한 6 개 강수사상의 평균 상관계수는 0.54 정도로 비교적 강한 양의 상관관계를 갖는 것으로 분석되었다. 그러나 앞의 3시간 분석결과와 마찬가지로 동일기간 동안의 $\mathrm{CMORPH}$ 강수와 지상관측 강수자료의 평균강수량은 $18.87 \mathrm{~mm}$ 와 $98.95 \mathrm{~mm}$ 로 약 5 배 정도의 차 이를 보이고 있다. RMSE의 변동성도 크게 나타나고
$\mathrm{N}-\mathrm{S}$ 계수도 매우 작은 값을 갖는 것으로 분석되어 앞의 3 시간 강수자료의 정확도 평가와 마찬가지로 지상관측 자료와 $\mathrm{CMORPH}$ 자료의 총강수량의 차이가 큰 원인에 기인하는 것으로 판단된다.

금호강 유역의 $\mathrm{CMORPH}$ 강수자료와 지상관측 강수 자료의 상관계수 분석에서 6 개 강수사상에 대하여 평균 0.44 정도로 3 시간 강수자료와 유사하게 '비교적 강한 양의 상관관계’가 있는 것으로 판단되었다.

Table 3. Comparison of CMORPH and Gauge data for $1 \mathrm{hr}$ accumulation precipitation

\begin{tabular}{|c|c|c|c|c|c|c|c|c|c|c|c|c|}
\hline \multirow{2}{*}{$1 \mathrm{hr}$} & \multicolumn{2}{|c|}{ CMORPH(mm) } & \multicolumn{2}{|c|}{ Gauge(mm) } & \multicolumn{2}{|c|}{$\mathrm{CC}$} & \multicolumn{2}{|c|}{ RMSE } & \multicolumn{2}{|c|}{ nRMSE } & \multicolumn{2}{|c|}{$\mathrm{N}-\mathrm{S}$} \\
\hline & ND & GH & ND & $\mathrm{GH}$ & ND & GH & ND & $\mathrm{GH}$ & ND & $\mathrm{GH}$ & ND & $\mathrm{GH}$ \\
\hline$\# 03$ & 13.67 & 13.09 & 50.25 & 43.53 & 0.41 & 0.51 & 1.95 & 2.01 & 0.58 & 0.43 & -2.24 & -1.42 \\
\hline$\# 04$ & 4.11 & 3.59 & 23.50 & 24.63 & 0.20 & 0.46 & 2.23 & 3.18 & 0.54 & 0.45 & -1.76 & -0.84 \\
\hline$\# 05$ & 26.33 & 29.21 & 117.99 & 117.07 & 0.62 & 0.46 & 1.69 & 2.65 & 0.24 & 0.19 & -0.09 & -0.03 \\
\hline$\# 06$ & 18.25 & 16.06 & 69.35 & 66.02 & 0.76 & 0.37 & 1.56 & 2.72 & 0.28 & 0.21 & -0.16 & -0.18 \\
\hline$\# 07$ & 28.53 & 29.36 & 133.90 & 173.36 & 0.49 & 0.37 & 2.11 & 3.86 & 0.34 & 0.24 & -0.90 & -0.37 \\
\hline$\# 08$ & 6.42 & 3.44 & 75.74 & 34.86 & 0.78 & 0.48 & 1.62 & 0.92 & 0.32 & 0.25 & 0.17 & -0.18 \\
\hline 평균 & 16.22 & 15.79 & 78.46 & 76.58 & 0.54 & 0.44 & 1.86 & 2.55 & 0.38 & 0.29 & -0.83 & -0.50 \\
\hline
\end{tabular}

\subsubsection{0분 강수 비교}

낙동강유역에 대해 30 분 자료에서 6 개 강수사상의 평 균 상관계수는 0.67 정도로 강한 양의 상관관계를 갖는 것으로 분석되었다. 그러나 앞의 3 시간 및 1 시간 분석결 과와 마찬가지로 동일기간동안의 $\mathrm{CMORPH}$ 강수와 지상 관측 강수자료의 평균강수량은 $16.8 \mathrm{~mm}$ 와 $78.48 \mathrm{~mm}$ 로 약 4.8 배 정도의 차이를 보이고 있다. 그러나 RMSE는 3시 간 및 1 시간 값보다 작게 나타나 변동성이 3시간 및 1 시간보다는 작은 것으로 분석되었다

시간해상도 관련해서 낙동강의 경우 상관계수 분석자 료는 3 시간, 1 시간, 30 분 각각 $0.67,0.54,0.67$ 이었고, $\mathrm{RMSE}$ 는 $6.77,1.86,0.90$ 으로 상관계수는 시간해상도의
경향성을 찾을 수 없었고, N-S계수는 모두 매우 낮은 것 으로 분석되었다. 다만, RMSE의 경우 시간해상도가 짧아 질수록 RMSE의 변동성이 작아지는 것으로 분석되었다.

금호강 유역의 $\mathrm{CMORPH}$ 와 지상관측 강수량의 30 분 자료에 대한 분석결과 상관계수는 3 시간 및 1 시간의 시 간해상도를 갖는 분석결과와 마찬가지로 '보통의 양의 상관관계’보다 약간 상회하는 0.46 정도로 분석되었다. 그 러나 RMSE는 3시간 및 1 시간의 값인 8.52 와 2.55보다 작은 1.28 정도의 값을 갖는 것으로 분석되어 낙동강 유 역과 마찬가지로 시간해상도 분석에서 상관계수는 경향 성을 찾을 수 없었으나 RMSE의 값은 시간해상도가 작 아질수록 변동성이 작아지는 것으로 분석되었다.

Table 4. Comparison of CMORPH and Gauge data for 30min precipitation

\begin{tabular}{|c|c|c|c|c|c|c|c|c|c|c|c|c|}
\hline \multirow{2}{*}{ 30min } & \multicolumn{2}{|c|}{ CMORPH(mm) } & \multicolumn{2}{|c|}{ Gauge(mm) } & \multicolumn{2}{|c|}{$\mathrm{CC}$} & \multicolumn{2}{|c|}{ RMSE } & \multicolumn{2}{|c|}{ nRMSE } & \multicolumn{2}{|c|}{$\mathrm{N}-\mathrm{S}$} \\
\hline & ND & $\mathrm{GH}$ & ND & $\mathrm{GH}$ & ND & $\mathrm{GH}$ & ND & $\mathrm{GH}$ & ND & $\mathrm{GH}$ & ND & $\mathrm{GH}$ \\
\hline$\# 03$ & 14.85 & 13.75 & 50.25 & 43.53 & 0.70 & 0.72 & 0.90 & 0.93 & 0.53 & 0.33 & 0.49 & -0.80 \\
\hline$\# 04$ & 4.92 & 4.56 & 23.50 & 24.63 & 0.51 & 0.28 & 1.08 & 1.57 & 0.50 & 0.43 & -1.53 & -0.63 \\
\hline$\# 05$ & 26.46 & 29.36 & 117.99 & 117.07 & 0.77 & 0.41 & 0.82 & 1.37 & 0.21 & 0.16 & -0.01 & 0.14 \\
\hline$\# 06$ & 18.29 & 18.29 & 69.50 & 66.09 & 0.86 & 0.44 & 0.75 & 1.37 & 0.26 & 0.20 & -0.07 & -0.15 \\
\hline$\# 07$ & 28.52 & 29.29 & 133.90 & 173.36 & 0.51 & 0.39 & 1.06 & 1.98 & 0.32 & 0.22 & -0.87 & -0.35 \\
\hline$\# 08$ & 7.79 & 3.91 & 75.74 & 34.86 & 0.67 & 0.54 & 0.80 & 0.47 & 0.28 & 0.22 & -0.26 & -0.11 \\
\hline 평균 & 16.80 & 16.53 & 78.48 & 76.59 & 0.67 & 0.46 & 0.90 & 1.28 & 0.35 & 0.26 & -0.37 & -0.32 \\
\hline
\end{tabular}


금호강 유역과 낙동강 유역의 유역 규모에 따른 분석 에서 낙동강 유역의 상관관계가 '강한 양의 관계 ( $\mathrm{r}=0.6 \sim 0.8)^{\prime}$ 를 갖는 값을 나타낸 반면 금호강 유역은 '비 교적 강한 양의 상관관계(r=0.4 0.6)'를 갖는 것으로 나 타나 유역 규모에 따른 자료의 정확도는 유역 규모가 커질수록 상관관계가 높아지는 것으로 분석되었다. 또한 $\mathrm{RMSE}$ 의 분석결과에서도 금호강 유역보다 낙동강 유역 의 변동성이 더 작은 것으로 분석되었다.

상관계수와 RMSE의 값을 통해 유역 규모에 따른 강 수자료의 정확도에 대한 평가에서 유역 규모가 커질수 록 위성으로부터 유도된 강수자료와 지상관측 강수자료 의 변동성이 작아지고 상관계수가 높아지는 것으로 분 석되었다.

\section{4 고찰}

위성으로부터 유도된 강수자료는 현장 측정이 대규모 홍수 또는 산사태와 같은 자연재해에 의해 중단될 수 있는 상황에서 매우 중요한 역할을 할 수 있다. 위성 강 수자료의 수자원분야의 이용에 대해 활발히 연구되고 있는 선도국가들에서는 광역적 홍수모니터링 시스템 개 발, 광역의 토양습윤과 국가농작물 생산평가 모니터링을 위한 실시간 운영 등에 위성강수자료를 활용하고 있다. 또한 위성관측 강수량 자료를 사용하여 자료동화 기법 을 통해 수치모델의 기초자료로 활용하여 수치예보의 정확도 향상은 물론, 강수기구 연구 등의 대기 물기과정 연구, 수문/수자원 관련 연구, 농업에서의 활용, 집중호 우와 열대 폭풍의 감시 등 많은 분야에서 그 활용이 증 대되고 있다.

물 산업의 해외 진출 또는 통일을 대비하여 북한 지 역과 같은 비접근 지역에 대한 수문학적 이해를 위해서 는 무엇보다 해당 지역의 강수 특성에 대한 연구가 선 행되어야 하며 이를 위한 유용한 자료가 바로 주기적으 로 관측되는 인공위성을 이용하여 유도되는 강수량 자 료일 것이다.

위성분야 선진국의 경우 1960 년도부터 인공위성으로 부터 기상영상 제공에 대한 시도에서부터, 위성 강수량 검보정과 관련하여 지상 관측, 레이더 관측 등을 포함한 집중 관측과 다양한 기후대를 망라한 지역에서의 상시 관측을 수행하는 등 많은 투자가 이루어지고 있으며, 수 자원분야와 직접적인 관계를 갖는 인공위성으로부터 유 도된 강수자료 $\mathrm{CMORPH}, \mathrm{TMPA}, \mathrm{GSMaP}$ 등을 인터넷을 통해 준실시간으로 제공하고 있다. 따라서 아직까지 국 내에서는 일부 기상학자들만이 관심을 가져온 위성을 이용한 강수량 추정 자료 및 기법에 대해 이제는 수문 학자들도 이들 자료에 대한 이해와 활용에 대한 관심을 가질 필요가 있을 것으로 사료된다.

Xie et al.(2011)에 의하면 2000-2009년의 10년간의 연
평균 강수량에 대하여 $\mathrm{CMORPH}$ 자료를 분석한 결과 공 간분포 패턴은 매우 잘 반영하고 있으나, 열대 및 아열 대 지역에서는 과대 산정되고 중간 및 고위도 지역에서 는 과소하게 산정되는 것으로 발표한 바 있으며, Sohn et al.(2006)에 의하면 CMORPH, PERSIANN, NRL-blended의 세 개의 위성강수자료에 대하여 520 개의 $\mathrm{AWS}$ 자료의 공간분포자료와 그리드별 격자비교를 통해 여름철 평균 분포는 명백하게 상당히 과소평가된다고 언급하고 있으며, 이는 한국지역의 PMW(Passive MicroWave) 기반의 강수자료 부족에 기인한 것으로 평 가하였다. 이는 본 연구의 위성으로부터 유도된 $\mathrm{CMORPH}$ 강수자료의 값이 작게 나타난 원인과 같은 결 론으로 나타나고 있다. 본 연구결과가 상관관계는 매우 높게 나타나지만 양적인 차이는 PWM를 이용하여 강수 량을 추정하는 알고리즘에 대하여 한국의 수문기상학적 여건을 고려한 알고리즘에 대한 개발의 필요성을 나타 내고 있다.

\section{4. 결 론}

본 연구에서는 위성으로부터 유도되는 강수자료의 수 자원 분야에서의 활용 가능성을 판단하기 위하여 유역 규모에 따른 분석, 그리고 시간해상도에 따른 분석을 수 행하였다. 분석결과를 요약하면 다음과 같다.

첫째, 한반도 남한에 대하여 1일 누가강수량에 대한 분석을 위해 2002년부터 2011년까지의 자료를 사용하였 다. 분석결과 상관계수가 0.82 0.91까지로 매우 강한 양 의 상관관계를 갖는 것으로 분석되었다. 또한 한반도 남 쪽의 $\mathrm{CMORPH}$ 자료와 기상청 69 개 기상관측소의 강수자 료에 대한 공간분포가 유사하게 나타나는 것으로 판단 되었다.

그러나, 지상관측 강수자료와 CMORPH 자료의 총강 수량 비교에서는 지상관측자료보다 $1 / 5$ 정도로 저평가 되 는 것으로 분석되었다. 이는 Xie et al.(2011)과 Sohn et al.(2006)이 제시한 결과와 본 연구의 위성으로부터 유도 된 $\mathrm{CMORPH}$ 강수자료의 값이 작게 나타난 원인과 같은 결론으로 나타나고 있다.

둘째, 유역 규모에 따른 분석을 수행하기 위해 낙동강 유역과 낙동강 유역내 금호강 유역으로 대상으로 분석을 수행하였다. 수행결과 유역 규모에 따른 자료의 정확도 는 유역 규모가 커질수록 상관관계가 높아지는 것으로 분석되었다. 또한 RMSE의 분석결과에서도 유역 규모가 클수록 자료의 변동성이 더 작은 것으로 분석되었다.

셋째, 시간해상도 분석을 위해 3 시간, 1 시간, 30 분 강 수자료를 분석하였다, 분석결과 상관계수는 경향성을 확 인할 수 없었으나 시간해상도가 짧아질수록 RMSE의 변 동성이 작아지는 것으로 분석되었다. 
상기의 내용을 종합해 볼 때 유역 규모에 따른 분석 에서는 유역 규모가 클수록 지상관측 강수와 위성으로 부터 유도된 강수가 상관성이 있음을 판단할 수 있으나, 시간해상도에 따른 영향은 추가 연구를 통해 판단해야 할 것으로 사료된다.

\section{감사의 글}

본 연구는 한국항공우주연구원의 위성정보 공공활용 사업(과제명: 위성영상을 활용한 하천정보생산 및 활용 에 관한 연구)와 한국건설기술연구원 주요사업(사업명 : 수문레이더 기반 고해상도 홍수해석 기술 개발) 연구비 지원에 의해 수행되었습니다. 이에 감사드립니다.

\section{References}

Alenmseged Tamiru Haile, Emad Habib, Tom Rientjes (2012). Evaluation of the Climate Prediction Center (CPC) morphing technique (CMORPH) rainfall product on hourly time scales over the source of the Blue Nile River. Hydrol. Process. 27, 1829-1839(2013)

Apip, Kaoru Takara, Yosuke Yamashiki, Kyoji Sassa, Agung Bagiawan, Ibrahim Hiroshi Fukuoka (2010). A distributed hydrological-geotechnical model using satellite-derived rainfall estimates for shallow landslide prediction system at a catchment scale. Landslide (2010) 7:237-258. DOI 10.1007/ s10346-010-0214-z

Augusto J. Pereira Filho, Richard E. Carbone, John E. Janowiak, Phillip Arkin, Robert Joyce, Ricardo Hallak, and Camila G.M. Ramos (2010). Satellite Rainfall estimates over South America - Possible Applicability to the Water Management of Large Watersheds. J. of The American Water Resources Assocuation 46(2): 344-360.

Korea Institute of Construction Technology(JICT), Korea Aerospace Research Institute(KARI) (2012). Satellite Information Application Support Operation : A Study of River Information Production and Application using Satellite Images(KOR).

Lee Giha (2012). Policy challenges for the water industry development and activation, Magazine of Korea Water Resources Association (10):8 12(KOR).

National Aeronautics and Space Administration(NASA) (2011). Tropical Rainfall Measureing Mission - Senior Review Proposal 2011.

National Institute of Meteorological Research(NIMR), Korea Aerospace Research Institute(KARI) (2009). "Development of Meterological Data Processing System of Communication Ocean and Meteorological Satellite" Final report(KOR).

Sohn, Byungju,Jaecheol Nam, Seonki Park, Myunghwan Ahn, Jungmoon Yoo,Heesang Lee, Dongeon Chang, Changhoi Ho, Deghyo Bae, Seongjun Kim,Hyunjong Oh, Seongchan Park and Juhong Kim (2005). Proposing Research and Development Activities for Utilizing the Global Precipitation Measurement (GPM). J. of Atmosphere, KMS, 15(1):47-57(KOR).

Tomoo Ushio and Misako Kachi (2010). Kalman Filtering Applications for Global Satellite Mapping of Precipitation(GSMaP), Satellite Rainfall Applications for Surface Hydrology, Springer, pp. 105-123.

Xie, Pingping, Soohyun Yoo, Rovert Joyce, and Yelena Yarosh (2011). Bias-Corrected CMORPH : A 13-Year Analysis of High-Resolution Global Precipitaton. NOAA's Climate Prediction Center(presentation) ftp://ftp.cpc.ncep.noaa.gov/precip/CMORPH_V1.0/ REF/EGU_1104_Xie_bias-CMORPH.pdf

http://en.wikipedia.org/wiki/Morph_target_animation http://www.cpc.ncep.noaa.gov/products/janowiak/cmorph_des cription.html

논문접수일 : 2013년 04월 16일 심사의뢰일 : 2013년 04월 29일 심사완료일 : 2013년 05월 27일 